\title{
TPP ash dump monitoring by ERS methods in the climatic conditions of Siberia
}

\author{
Natalia Kruk ${ }^{1}$, Mikhail Merko ${ }^{1}$, and Inna Merko \\ ${ }^{1}$ Cand.Tech.Sc., Siberian Federal University, Krasnoyarsk, Russia
}

\begin{abstract}
A comprehensive monitoring procedure for TPP ash dumps in the climatic conditions of Siberia is proposed, which involves implementation of two stages. At the global stage, remote sensing technology is used directly from spacecraft in Earth's orbit, while at the regional stage, an unmanned aerial vehicle and numerical modeling are used. An example of the operations is given, which clearly shows how exactly this procedure will increase efficiency of the TPP ash dump monitoring in the climatic conditions of Siberia and help promptly take measures required to prevent collapse of the ash dump external soil structure, which may result in ash and slag waste outflow and contamination of the adjacent territory.
\end{abstract}

At present, the problem of environmentally safe storage of ash and slag from TPPs is very acute. At TPPs of the CIS countries, more than 100 million tons of solid fuel were generated annually from the combustion of solid fuel, and over 1.5 billion tons of ash and slag wastes were accumulated in dumps. TPP ash dumps have a negative impact on the environment (pollution of surface and ground waters during filtration of toxic wastewater, overflow and destruction of dams, wind erosion of stored waste and pollution of the atmosphere and soil, destruction of natural landscapes, and hazardous cryogenic processes). In this regard, the problem of monitoring the increasing TPP ash dump volumes aimed at preventing environmental pollution will become more and more pressing [1].

Local environmental monitoring systems are envisaged to monitor and assess the environmental situation for the operation of ash dumps with earth dams, including an analytical visual and instrumental control complex [2,3]. Most ash dumps and other similar ponds have local environmental monitoring systems reduced to visual observations, which are carried out through rounds and inspections of structures of this type once every six months, and mandatory recording of the results obtained in the observation log. However, analysis of the observation results and the existing environmental pollution show that this number of visual observations is clearly not enough, for they do not enable prompt identification of the ash dump soil structure deformation at the initial stage. This is especially evident in spring accompanied by a phase transition of the soil massif from frozen to thawed state. This results in the emergence and subsequent development of all kinds of cracks on the ridge, slopes and berms followed by accidents at ash dumps with the ash and slag waste outflow into the adjacent territory, and environmental pollution (Fig. 1). 


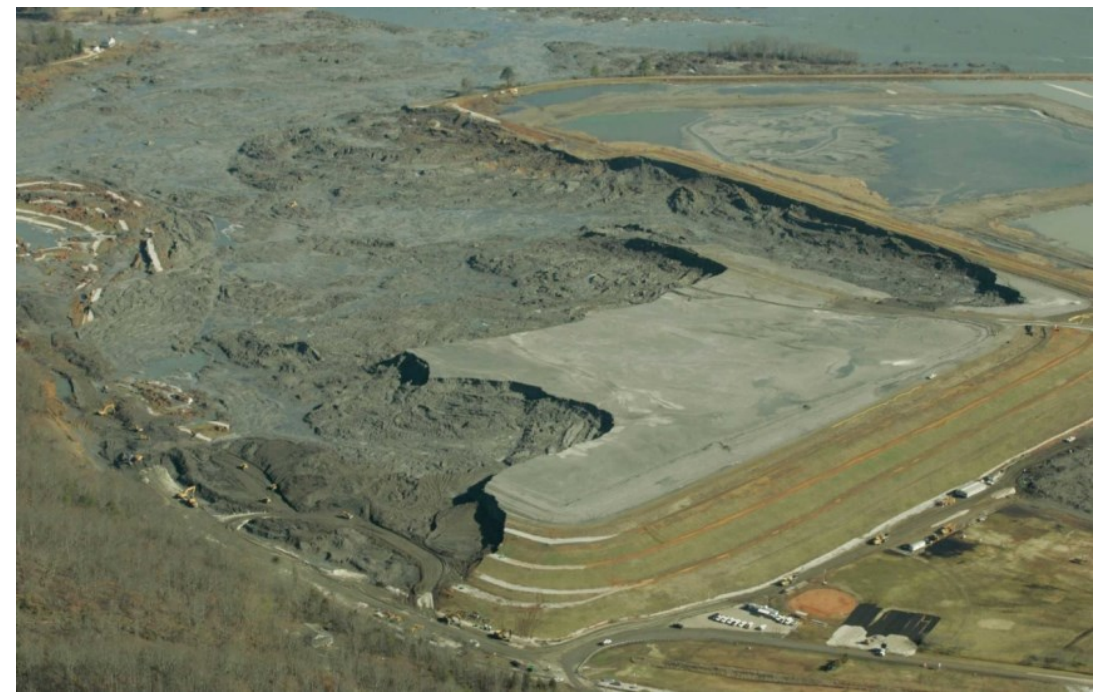

Fig. 1. Ash and slag waste outflow with contamination of the adjacent territory

Solution to this problem is possible through the use of a dry ash and slag waste storage technique with ash dump formation, which is rather difficult today due to the increased bureaucracy of TPP managing companies and, generally, does not solve the problem of monitoring the state of existing ash dumps. In this situation, increasing the ash dump monitoring efficiency comes to the fore, which relies on remote sensing technology, unmanned aerial vehicles and modern software for processing the observation results obtained. This will make it possible not only to increase the number of control operations, but also to improve the quality of the operation results for the purpose to develop an integrated TPP ash dump monitoring procedure in the climatic conditions of Siberia.

The proposed integrated monitoring procedure should include the following activities:

Global stage. This involves the use of remote sensing technology directly from the spacecraft in the Earth's orbit. The operation must be carried out in accordance with existing regulations once every six months.

As a result, we obtain high-quality images of the enclosing dam outside and the ability to scan the soil massif vertically from the ash and slag deposit upper layer in the pond zone in order to detect initiation of any karst cavities, suffusion outflows and other inside deformation processes, which are not available for visual inspection. Other deliveries may include images of the water level in the pond zone, changes of the settling pond bottom level, stored waste capacity, the speed and power of the sluiced ash and slag material, changes in the structure contours in plan, transverse and longitudinal sections of the enclosing dams, build-up dam body soil, and establishment of soil slopes. The combination of the above data makes it possible to more accurately build a design section of the ash dump necessary for the numerical modeling of industrial wastewater filtration and calculation of the enclosing dam slope stability.

The research data will make it possible to identify and subsequently evaluate:

- changes in the dam crest, slopes, and condition of the structure foot;

- uncontrolled filtration outlets through the dam body and its base;

- points of filtration-suffusion soil removal from the structure and foundation;

- swamping areas in the territory adjacent to the structure foot in the lower pool;

- development of tree and shrub vegetation on the external soil structure within the sanitary protection zone and beyond. 
Based on the global stage results, a program of activities is formed to be implemented at the subsequent regional stage.

Regional stage. We envisage the use of an unmanned aerial vehicle for monitoring. This operation can be carried out at the initial stage of information accumulation once a month. Based on the results of processing the information obtained, a more accurate picture of the state of the ash dump and the adjacent territory is formed. This will help more closely monitor the state of the ash dump in accordance with the program of activities developed with the global stage results, in particular:

- all kinds of cracks on the ridge, slopes and berms;

- ice formation on the downstream slope;

- signs of frosty weathering of ash and slag waste;

- development of grass cover and the behavior of earth-moving animals.

This stage will also provide an opportunity for monitoring the state of the environment in the form of observations:

- turbidity in the water of reservoirs formed in the lower pool as a result of filtration;

- erosion and caving of the structure and the banks from the lower pool side.

The program of further activities is then verified following the regional stage results. If any suspicious areas are identified, they are paid special attention, i.e. the number of inspections performed using an unmanned aerial vehicle can be increased up to twice a month, and if an unfavorable scenario develops, these operations can be carried out weekly.

To confirm the relevance of monitoring, let us consider it using the example of ash dump No. 1 at Krasnoyarsk TPP2.

Global stage. The satellite image of ash dump No. 1 is processed in the SAS.Planet.Release.191221 program. The result is shown in Fig. 2a.

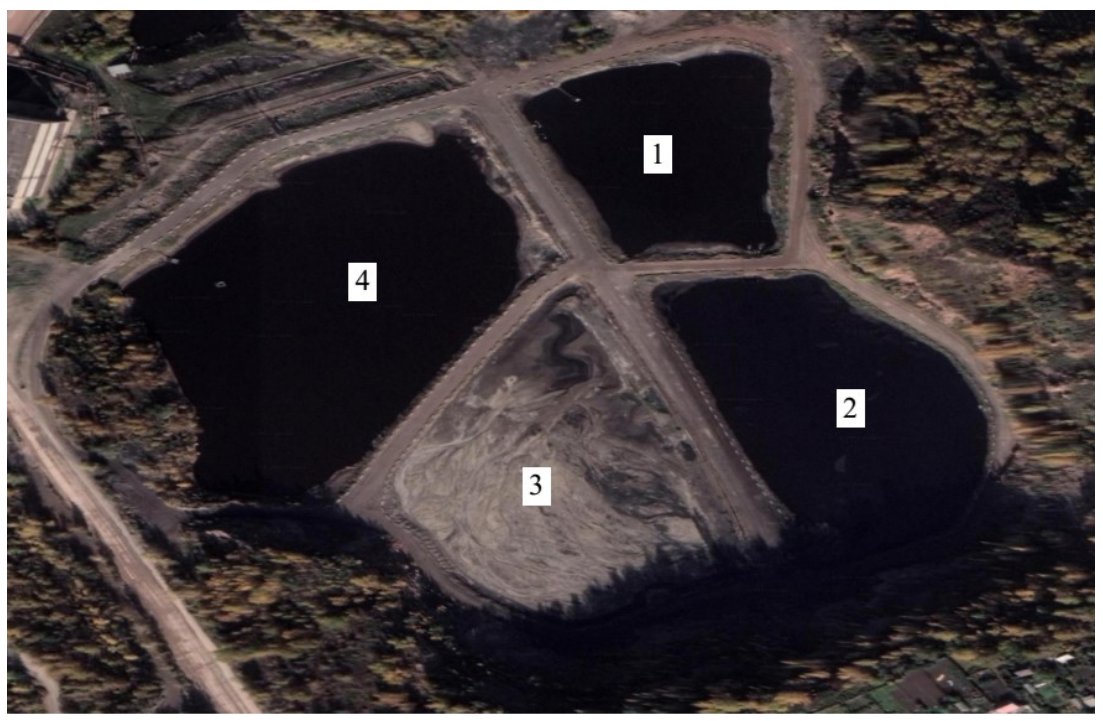

Fig. 2a. Results of ash dump No. 1 monitoring at the global stage

Analysis of the image (Fig. 2a) shows that at the time of shooting the ash dump No. 1 was in the following state:

- sections No. 2 and No. 3 are operational, however, at the moment ash and slag is washed into section No. 2, and section No. 3 is already filled and is in the mode of ash and slag dehydration to a moisture content of no more than $50 \%$;

- section No. 1 is intermediate and is used to discharge water from sections No. 2 and No. 3 using bypass pipes located in the separation dams [3]; 
- section No. 4 is used as a pond for storing clarified water coming from section No. 1 [3].

This means that the main attention should be focused on monitoring the state of section 3 , although we continue to monitor the rest of the sections as well.

To obtain more accurate information about the state of ash dump No. 1, we subject the image (Fig. 2a) to analysis using the ENVI 4.4 program. The result is shown in Fig. 2 b.

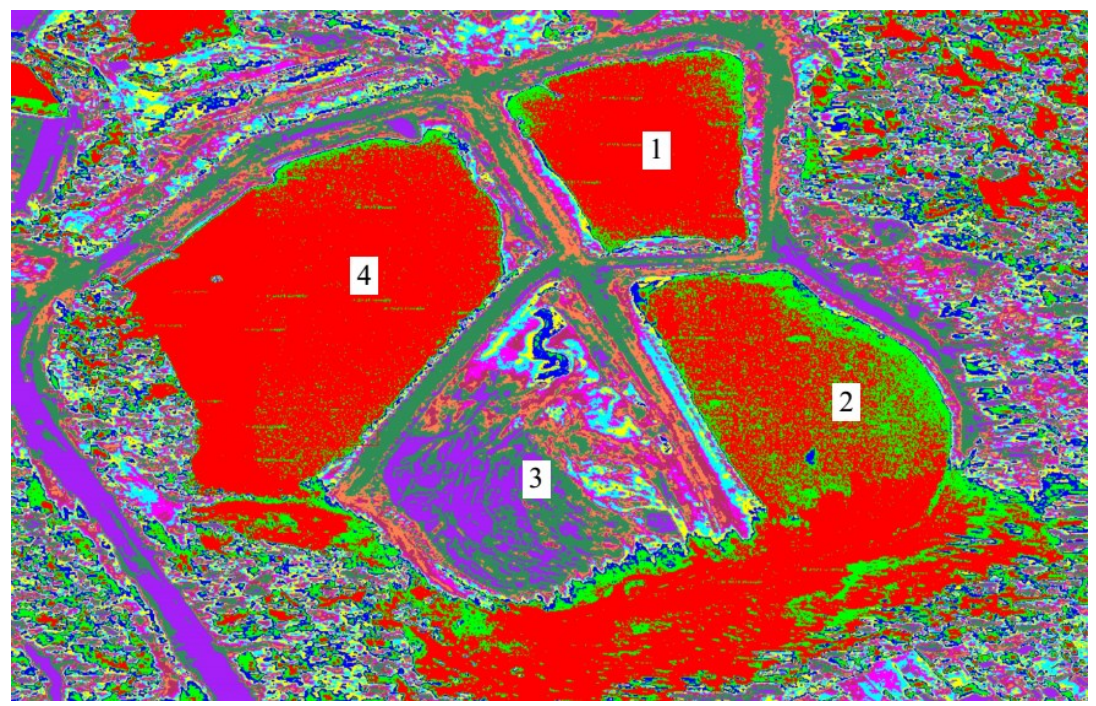

Fig. 2b. Image 2a analyzed using the ENVI4.4.

Analysis of Fig. 2b shows that the main water flow runs to the center of ash dump No. 1 , where the system of bypass pipes is located, which means water drainage into section No. 1. However, the right edge of section No. 3 has a clearly visible trail of water flow to the separation road between sections No. 3 and No. 2. This means that this area needs to be taken under more careful control, which we are monitoring at the regional stage.

Regional stage. We collect additional data on the state of the area of special attention and analyze it, which enables us to consider the influence of the data obtained about this part of the ash dump No. 1 on the dependence of the depression curve position on the configuration of the calculated filtration area boundaries. The research is carried out within the framework of filtration analysis in two directions:

- option 1: we take into account the role of the inwashed layer of ash and slag waste when filling section No. 3 of the ash dump No. 1 to a mark of $138 \mathrm{~m}$, and we assume the lower reservoir as the unloading circuit of the filtration flow;

- option 2: we take into account the role of the inwashed ash and slag waste beach of section No. 3 of the ash dump No. 1 from ash and slag waste.

For both options, we perform numerical modeling of filtration in a flat-vertical setting [5]. The algorithm and the calculation program take into account general provisions of the finite difference method and the initial research data. We obtain the filtration flow data, which is further used to form the filtration models for both options of the study as shown in Fig. $3 a$ and $b$.

Analysis of the filtration models (Fig. $3 \mathrm{a}$ and $\mathrm{b}$ ) enables to determine position of the depression curve, distribution of pressure heads in the filtration area, parameters of the seepage area and several types of filtration flow rates. 


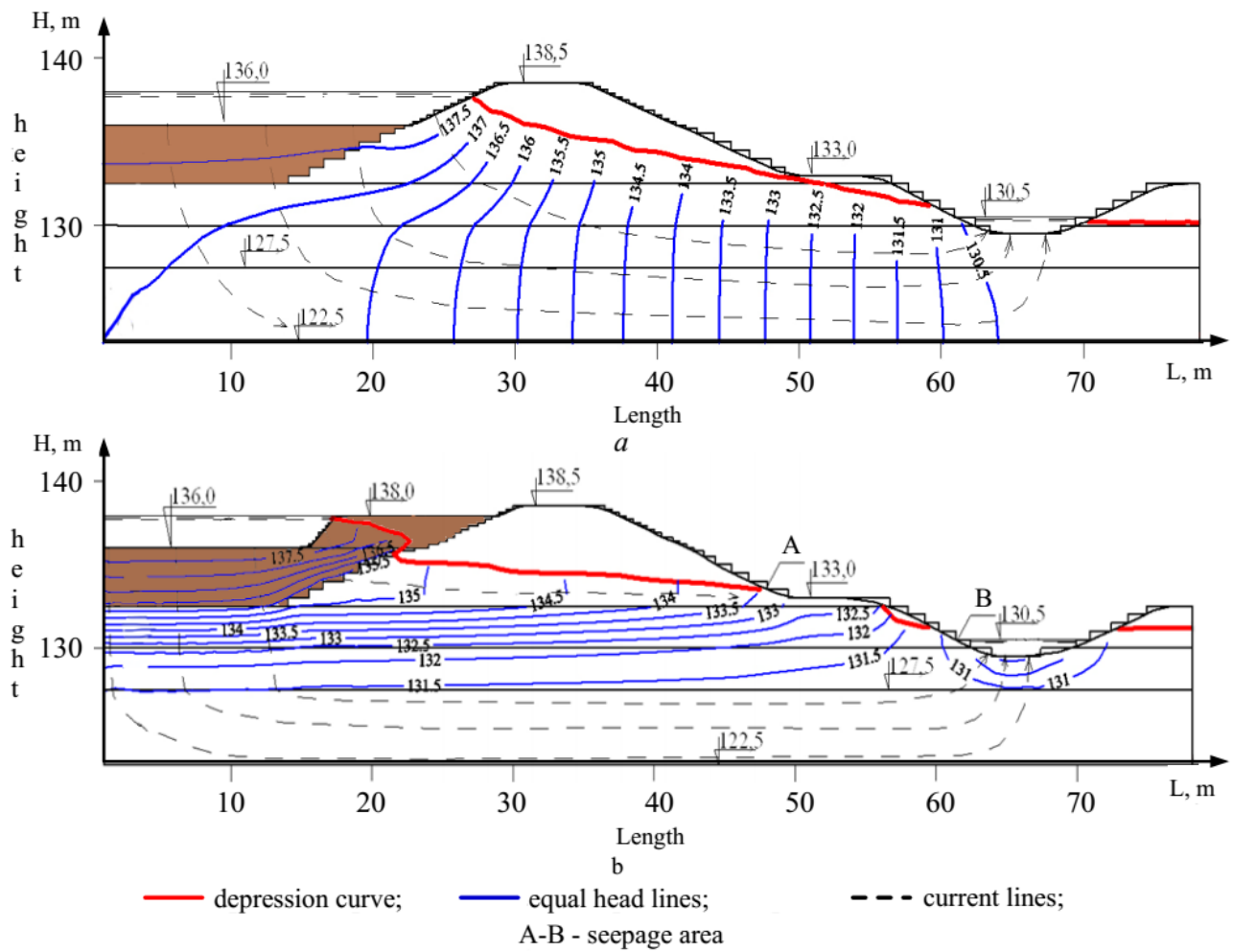

Fig. 3. Model of filtration from the second section of the ash dump: a - Option 1; b - Option 2

Comparative analysis of filtration models between options 1 and 2 (Fig. 3 a and b) shows that the depression curve position depends on the adopted configurations of ash and slag wastes inwash inside the ash dump bowl. In this case, it is clearly seen that in option 2 (Fig. 2b), the depression curve is located much higher than in option 1 (Fig. 2a), which means that the filtration flow seepage runs towards the lower slope and can result in pollution of the environment.

The use of remote sensing methods in monitoring of TPP ash dumps allows for an expansion of the modeling capabilities by using more accurate data due to covering of the following parameters:

- complex configuration of internal and external boundaries of the designed filtration area;

- various boundary conditions, changing in stages during the massif formation;

- the stages of the ash and slag waste massif inwash under the water level in the settling pond.

The proposed integrated monitoring procedure will improve efficiency of monitoring of TPP ash dumps in the climatic conditions of Siberia and help promptly take necessary measures to prevent collapse of the ash dump enclosing dams, which may cause contamination of the adjacent territory as a result of the ash and slag waste outflow.

\section{References}

1. G. I. Kuznetsov, N. V. Kruk, Engineering geocryology: study guide. SFU, Krasnoyarsk (2019) 
2. GOST R 57793-2017 United power system and isolated power systems. Hydraulic and pumped storage power stations. Hydraulic engineering structures. Monitoring and assessment of technical condition during operation. As of 1 July 2018. Standartinform, Moscow (2017)

3. STO 70238424.27.140.035-2009 Hydroelectric power plants. Monitoring and assessment of the technical condition of hydraulic structures during operation. As of 31 Dec. 2009. Moscow (2009).

4. Draft technical documentation Ash and slag material obtained as a result of operations of JSC Yenisei TGC (TGC-13) Krasnoyarsk TPP2, Assessment of the impact of planned activities on the environment, Book 1, Explanatory note, Kemerovo (2017)

5. Y. M. Sysoev, Ash dump design and construction, Energoatomizdat, Moscow (1990) 